\title{
Health related quality of life of women suffering from Uterine Prolapse before and after six months of surgery
}

\author{
Anchala Chaudhary \\ Central Department of Sociology/Anthropology, Tribhuwan University, Kathmandu, Nepal; anchalachaudhary@yahoo.com
}

Received 17 December 2013; revised 22 January 2014; accepted 31 January 2014

Copyright (C) 2014 Anchala Chaudhary. This is an open access article distributed under the Creative Commons Attribution License, which permits unrestricted use, distribution, and reproduction in any medium, provided the original work is properly cited. In accordance of the Creative Commons Attribution License all Copyrights (C) 2014 are reserved for SCIRP and the owner of the intellectual property Anchala Chaudhary. All Copyright (c) 2014 are guarded by law and by SCIRP as a guardian.

\section{ABSTRACT}

One of the goals of health for everybody in $21^{\text {st }}$ century is the improvement of quality of life. Thus, to find the best treatment for medical problems, it is not only enough to evaluate the results of interventions on morbidity and mortality in clinical studies, but also that the outcome of interventions in terms of socio-cultural aspect should be evaluated. Uterine Prolapse strikes at the heart of a woman's sense of her own women nature and therefore her security along with her marital relationship should be guaranteed after the surgery process. After the removal of uterus women can't find herself fulfilled though it is sick one as changes appear in women's life both in understanding of her health as well as socio-cultural position that they gained after being as women. Many of the women who underwent surgery process are still suffering from both physical and psychological impairments. Some of them are experiencing psychological problem as they feel no longer a whole or real woman because of the removal of their reproductive organs, while others still had an orgasm from intercourse not just feeling dead. The changes to their sex life have created problem to them as they still struggle to cope with the loss they feel in their life as husbands always fed up as they argue with him. Such types of suffering and pain happen due to the socio-cultural circumstances in which a woman is brought up. They are seen as productive machine which had never been stopped though they are passing from pain and suffering. Thus, the overall issue of surgery process is to assure the quality of life of women to be them as a good wife and mother as well as good employer outside the home but before all this feeling of a whole womanhood in their life.

\section{KEYWORDS}

Uterine Prolapse; Quality of Life; Perception of Life; Socio-Cultural Practices

\section{INTRODUCTION}

Like in many other developing countries, poor reproductive health among women has been a major public health problem in Nepal. Deep rooted religious and cultural traditions as well as ethnic and cultural diversity may be the reason for poor reproductive health. Additionally, many social norms based on the religious cultural traditions are found partially responsible for health problems of women and in particular their reproductive health is severely affected by their low familial and social status, patriarchal perspectives, traditional values, illiteracy, poverty [1]. Although the women's health agenda has been largely defined by biomedicine and public health, anthropology has much to offer in terms of defining and understanding women's health from perspective of women themselves [2]. The issues of women's health are acute problems among health and development workers all over the world. The Cairo Conference (1994) and Beijing Conference (1995) have stressed the need of research to address the issues of women's health problems employing holistic approach.

Uterine Prolapse (UP) is one of the most widespread reproductive health and social problems in Nepal, which has become an issue of a national tragedy [3]. Uterine Problem is wide-spread across the country and has affected women in the mountains, hills, plains and the val- 
leys of Nepal. In addition, for UP there is no age group difference for this problem and women as old as eighty may be the sufferers. Nepal Demographic and Health Survey (2006) data show that up to $7 \%$ of women of reproductive age group (15 - 49 years) were suffering from Uterine Prolapse. Also the report showed that $6 \%$ of women who had ever given birth experienced symptoms of prolapse [4]. Uterine Prolapse is defined as falling of the womb, when the muscles of the pelvic are strained to a point where they can no longer support the positioning of the uterus. The Uterus drops from its normal position in the pelvis cavity, descending into and eventually, in the extreme stages, out of the vagina. It is a progressive condition that typically occurs in post-menopausal women in most countries. However, it can also occur in younger women [5], and frequently does in Nepal. Uterine Prolapse is usually classified into four anatomical stages corresponding to the severity of the condition [6]. For the first stage, the uterus leaves its place but is still inside the vagina. In the second stage, the uterus leaves its place and comes up to the opening of the vagina. For two lower stages (I and II), conservative managements including pelvic floor muscles training or ring pessary insertion are considered the best options [6].

Women in Nepal are victims of social, economic and political discrimination, including in matters relating to health; they serve triple roles as wives, mothers and homemakers. In the capacity of a homemaker, they are responsible for cooking, cleaning, taking care of domestic animals and most of these duties require intensive physical labor. They do not get a break even during pregnancy or right after delivery. Moreover, they do not have equal voice in birthing gap or the number of children they want to have. Extensive physical labor soon after delivery or during pregnancy, along with low availability of skilled birth attendants, smoking while COPD (Chronic Obstructive Pulmonary Disease), low maternal weight due to lack of nutritious food, lack of proper health awareness are risk factors for UP [5]. The debilitating aspects of these conditions extend beyond physical impairment for the concerned individual. These women also tend to avoid sexual intercourse because it is not pleasurable but painful. Moreover, women with genital prolapse are considered impure in the Nepalese society and hence start getting neglected by their husbands [6]. The body dysmorphism in addition to concerns of the husband wanting to re-marry causes these women to lose self-confidence and depression. UP patients are either disabled in performing their perceived social roles as wives, mothers and homemakers or perform them with serve pain. In either case, eventually their quality of life is seriously compromised.

Thus, the only remedy to this problem is a hysterect- omy in which the uterus is surgically removed. Official records indicate that 24,498 women have already received a free Uterine Prolapse surgery between the fiscal years 2065/2066 to 2067/2068 [7]. However, the health condition of women who received surgery is unknown. Therefore it is desirable to know whether or not the women received follow up service after surgery, whether their health status has improved, what their perceptions and experiences of the service entailed and their daily life after surgery. In this research I have explored the health related quality of life of women before and six months after surgery including the perception about health status before and after Uterine Prolapse. The level of patient's satisfaction after having the surgery as well as their socio-cultural status in their own society after the removal of uterus was also noted down.

The beliefs, ideas and understanding in regards to UP are a serious reproductive health problem which has inspired me to work in this sector. However the understanding about UP depends on the nature and type of society that construct the meaning of health and illness. Thus, the understandings and contexts that shape action and decision-making about any reproductive health are not static, but changes over time, across geographical space, and through social relationships and dynamics. Considering that causes of UP have changed throughout the course of society, prolapse can be dually considered as a biological determinant but also as an outcome of social factors.

In order to understand the health conditions of women before and after the UP surgery, I have focused this study to provide the answers to the following questions:

1) What challenges did they face during the course of having surgery and afterwards?

2) Do the women feel that having the surgery was the right decision? If yes, how and if not, why not?

3) What is the current quality of life of women (physical including sexual, mental and social parameters) who have undergone Uterine Prolapse surgery?

The basic method of data collection for this study was based on the key informant's interview along with some relevant cases. Interviews with different patients took place at their home only after building a good rapport with them. The primary respondents of this study were women who undergone UP surgery before the six month of my study conducted. The secondary sources of data were collected through the related literature. Face-to-face in-depth interviews with women were used as research tools for the data collection. In the process of performing interview, I also have been successful in collecting some case study of my respondents which adds to the interpretation of the data in narrative way with the real scenarios of women who had undergone the surgery process. 


\section{THEORETICAL FRAMEWORK}

I draw on the theoretical framework of Ruth Finney Hayward (2000) to look at women health from perspective of gender. Her book, "Breaking the Earthenware Jar" (2000) is a story of courage and hope for the women and men from South Asia for ending the problem of violence against women and girls, both in the family and outside it. On the one hand, gender based violence is seen as a development and human rights issues on lives, potential and rights of all affected children, men and women whereas on the other the outcome of gender based violence is affecting the women's health by creating socio-cultural difference between man and woman in performing different kinds of work [8]. Hayward's book plays an important role in challenging the patriarchy and feminity that underplie it, which are important strategies for change. It also raises the many health related issues for ending the discrimination faced by a woman in their own family, society and across the nation.

I also draw on Ellen Annandale and Judith Clark (1996) and Ellen Annandale and Kate Hunt (2000) for insight into looking at gender inequalities in health and human reproduction. They all tried to focus on women's health in relation to their access to education, employment, health and the way by which women suffer from low status of health by creating women body as inferior, deficient associated with illness in their own family and society which is of patriarchal in nature [9]. At the most general level, they all tried to show that women's experience of health is socially constructed rather than built directly upon biology or the materiality of the body.

My theoretical frame moves in between them. I have tried to use both of these frameworks with their original sense in relation to a special problem faced in women life which is termed as UP. My aim throughout this present study is to look at women's health as not as biological problem but as the outcome of society in which a girl is brought up as a result their roles and responsibilities is much higher than that of men's. Not only this but the deep rooted thought of early marriage and preference of son put them more in problem which not only deteriorate their health but also make them suffer from psycho-social problem in near-by future. This later on traps them in problem and makes their own body un-wanting and discussion of every mouth as a problem. In relation to this, women's health has been defined as their access over education, employment, means of resources and knowledge's about health problem within their own cultural contexts.

\section{CHARACTERISTICS OF WOMEN HAD UNDERGONE THE UP PROBLEM}

The distribution of women was based on background characteristics, including age, caste, type of family, education status, occupation and annual family income. Most of the women who had undergone surgery were above the age of 40 belonging to Chhetri community and lived in nuclear family. Of them, two were separated from their husbands after the UP problem were diagnosed which created hard situation for their survival latter on. Most of them got married before the age of 20 and only few of them who married after 20 hence prevalence of early pregnancy was very high with son preferences. Although the level of education was somehow good, it was revealed that many of them did not have any knowledge about UP and its treatment before visiting the hospitals; they felt embarrassed while consulting their physicians even if they had the knowledge which eventually affected their quality of life latter on. A highly educated women working in medical field belonging from Katmandu valley, who was a case of UP problem, shared her experiences as:

Although I was working in hospital and almost in the field related to UP, my journey has been long and traumatic. As I hold intermediate degree and had knowledge about causes and consequences of UP, I didn't care when I noticed $1^{\text {st }}$ degree prolapse which was deteriorating quality of my life slowly and gradually. I suffered for long 9 year, there was no one in my home to do the household activities and I had to go office regularly. I was operated in a few months back. But after the operation, I had to start immediately my works both in office and in my home. As a result, I still have to face some difficulties like backache while sitting and walking. Though I knew the reasons for the problems were lack of proper rest immediately after the operation, I had to return to my duties and responsibilities.

After finding the reasons behind such causes, the role and responsibilities that a woman has to perform as housewife as well as an employee made them trap in double bond of work. The majority of respondents were employed in some kind of work beside household activities. Some of them enrolled in governmental sectors while other had involved in business, daily wages and other occupations. Only few were involved in agricultural sectors as their part time work. Most of the women reported that their annual family income was more than fifty thousand while there were only few of them who said that their annual income was low that makes them hard to sustain as they were separated from their husbands.

The place where I conducted this research is highly developed where the rate of literacy along with other facilities such as: hospital, colleges, school, electricity, road etc. are high in proportion than that of other part of the country. But at same time traditional norms and values are still in existence in apparent form. Still most of 
the women had to perform their household activities along with their official one. A boy can't help her though he is free due to his traditional mind set. Most of the women argued that their roles and responsibilities were increased after knowing the problem as they had to take care of themselves too. One of the respondents who as 36 years old from Chhetri community shared her experience as follows:

I was married at the age of 18 and my first child was born after one year of our marriage. Though our families are educated and economically strong but this does not make me free to enjoy my life as I had to take care of children as well as my husband too. After two year, my second child was born and my responsibility increased with the increase in number of children. As we were living separately from our parents and there was no one to help me soon after my delivery, I had to carry my household chores by myself and then take care of child. Cooking food was easy but I did not get proper rest after and soon after this I was faced with the first degree of UP but didn't share with anybody as I had to fulfill my responsibilities and also due to shame and shyness. But after ten years my problem did not lead me to keep silent and I shared with my husband and I was operated in the month of June but after the operation too I had to carry my household chores and there was no one to help me as we were living separately from our family and also my husband had to go for office and my both child went schools.

Son preference leads to multiple pregnancies and female foeticide is a common practice; this eventually makes women more prone to UP. My concern of arguments presented are that if this is situation faced by a woman of highly developed society where the root of patriarch is present in same manner as that of women belonging from less developed society who are still far from light of education and awareness level. Still there are more women who don't raise their voices for their own rights but helps in nourishing the foundation of such society. Though, the bodily integrity rights have given woman an automatic veto over the man's procreation decision once she could take the decision regarding about reproductive rights but at the mean time she fails to overcome this decisions. Therefore, women's experience of health is socially constructed rather than built directly upon biology or the materiality of the body.

Not only this, but a belief about the role of women that she has to performed household chores, take care of the family and produce children for long as they are able put them under the pressure of over burden of works which slowly and gradually deteriorate their health. However, the work of women performed in home is less valued than that of work performed by men outside their homes. Because of the household labor is unpaid and associated with lack of power, whereas on the other hand the more powerful spouse performs the least amount of household work. As a result women can't control and limit the role played by her in family and had to do their household activities regularly without any disturbance in the life of their children as well in husbands.

\section{WAY OF DETERIORATING QUALITY OF LIFE}

Quality cannot be defined only in clinical and technical terms. Quality should be both cultural sensitive and gender sensitive. In this sense, the quality of health of women should be holistic in approach to include selfesteem, personal autonomy, freedom from violence and sexual choice as Feminist theory has argued. The WHO definition of reproductive health extends beyond the physical aspects of health to include mental and social well-being [10]. A quality service attempts to capture all aspects of the definition. This means that reproductive health service programs must take into account the social context in which women live.

Women shared that they had been experienced of emotional abuse from their companion and humiliated in front of other people after seeing the UP problem. Not only by husband but also the other family member and neighbors' make them isolated from doing any ritual performances as they were suffering from flow of white discharge problem. This hampers in the quality of life along with the rate of survival rate as they feel anxiety and perception and experiences about daily discomforts was taken easily by their family members. A case of 36 years belonging from Chhetri community demonstrates the feeling as she faced after the knowing UP in such a way that gives reality that a woman should face being a woman:

When I was suffering from UP, I was feeling humiliated as I was unable to help my husband in his business and also in household chores. Later I did not want to talk to anyone for sharing my problem as there was no one to listen me which latter on forced me to withdrawal from social activities. My mother-in-law along with my husband always said to me, "You can't work! Why are you only at home? I couldn't work due to my internal problem which gave me pain, so I felt humiliated." This gave me a lot of suffering both physically as well as mentally. But after the surgery in the month of July (2011, A.D.), I was able to perform the usual works normally and also started to help in business. All family members along with my husband is satisfied with me but at the same time I could not take a proper rest due to which I still felt pain in back ache and have been taking medicine regularly.

Most of the women were still suffering from physical impairments and face difficulties in walking and sitting for the long period of time as well as low back pain after their UP surgery. Physical weakness along with conti- 
nuous thirst phenomenon was complained by some of them while other faces problem like leakage of urine. Their life was not comfortable before operation though they were living in highly advanced area with well-educated family. They also argued that due to their leave balance in office they had to join their job which makes them psychologically ill. A 48 years old lady from a well-educated Brahmin family who was a school teacher expressed her experiences as follows:

$I$ was really uncomfortable always when I was out of home before the operation. I always had to carry a sanitary napkin for leakage of urine. This put me on stress while I was out of my house and this limited my role outside home. Also I couldn't sleep well at night which made my life more stressful day after day. But after the operation in the month of May (2011 A.D.), I felt so happy having a good physical and mental health with a sound sleep.

The conjugal life changed as the sexual act were not pleasant for both of them and as the act was painful for the female partner eventually put the relation under stress. A 52 years educated Newari woman from Katmandu valley who is now enrolled in well-reputed organization as an employee in medical field shared her experiences as mentioned below:

After diagnosis of the UP problem my husband and I became very sad though we knew that it was treatable. I was refrained from doing any work and my personal relationship with my husband was stressed; though he didn't express, I understood. We had no sex continuously but whenever we tried, both of us felt discomfort and pain. He does not like to have sex with me now days too, though I was operated out and having no problem.

Thus it seems that the quality of life, both physically and mentally, of women is not changed much as they were not satisfied with the personal relationships with their husband before and after the operation. After six month of period too, women find difficulties in their sexual relationship with their husbands, which doesn't necessarily mean negative relationship with their husbands but give message that they are still not acceptable culturally even after surgery.

\section{PERCEPTION ABOUT HEALTH STATUS BEFORE AND AFTER SURGERY}

Provision of high-quality care should be client centered and based on their needs, attitudes and concerns which in turn affected by personal, social, and cultural factors. Researches highlight the benefits of addressing client perspectives on quality of care, since it leads to improved client satisfaction, continued and sustained use of services, and improved health outcomes [11].
Quality of care is beyond the concepts of clinical setting rather it is concerned with the perception of person possess before he seeks medical treatments. In case of UP related issues, the women's perceptions are shaped by their cultural values, perceptions of the role of the health system as well the interactions with service providers and so on. As most of these women are not empowered, they have little access to material resources and to some extent physical mobility which shapes their health seeking behavior in a negative way. Thus they are little concerned regarding the quality of services provided, rather they are concerned whether they are getting well soon or not and whether they are returning to relatively normal life both mentally and physically or not.

The experiences of UP in life was encounter mostly below the age of 35 years, few within the age group of 40 - 45 years. Similar finding was observed in a study conducted by SAIPAL, WHO and FHD (2011) in Doti District where $50 \%$ of women suffer from UP problem by the age of 25 years. Most of them said that doctors have detected the third degree of prolapse before surgery (hysterectomy). Surgery itself poses some deleterious health effects. In a study conducted in Doti District it was revealed that $72 \%$ of women were suffering from ill health before surgery. Most of them felt difficulties in walking and sitting, low backache, difficulty in defecation, constipation, and lower abdominal pain and foul smelling whitish discharge and dysparunea; while few of them reported increased frequency of micturation, sweating, feeling of something coming out per vagina while carrying heavy weight.

Surgery is the only remedy for third degree Uterine Prolapse. Although biomedicine clearly has the power to heal and some technologies are, indeed, lifesaving, require constant surveillance and vigilance to prevent unnecessary medical control over women's lives [2]. As process effects on the quality of life of women directly or indirectly as it creates new problems such as pelvic/abdominal pain, urinary problems, constipation, weight gain, fatigue, lack of interest or enjoyment in sex, depression, anxiety and negative feelings about oneself as a woman. Quality is not assured only in clinical setting but also in terms of their socio-cultural form in which they were living. So, after such surgery women should have quality life. However it is discouraging to note that most of the respondents were not satisfied with their life after surgery, supported by similar findings in a study conducted by SAIPA, WHO, and FHD (2011), conducted in Doti District which showed that $40 \%$ of women had experienced complication after they did surgery.

\section{CONCLUSION}

The physical, mental and social well-being of the people 
in the society is the most important factor for social and economic development. The aim of Second Long Term Health Plan (1997-2017) was to improve the health status of the population; particularly vulnerable groups whose health needs often are not met, including women and children, the poor, and underprivileged and marginalized groups. However, this plan would address disparities in health status, assuring equitable access to quality health care services with full community participation and gender sensitivity. Despite such target, the study conducted by UNFPA in 2007 found that 600,000 women suffered from UP while more than the number of people are suffering from Malaria, Tuberculosis and HIV/AIDS combined, among which 200,000 needed surgeries immediately [12]. Still, there are scarcities in scientific papers and study conducted in Nepal in this field, this study not only provides magnitude of the UP problem in urban area but also focused on their quality of life after surgery.

Since uterus is women's main reproductive organs and symbol of womanhood, its removal may change a woman life both in understanding of her health as well as in terms of socio-cultural position they gained after being as a woman. As improvement of maternal health thereby improvement of quality of life is one of the goals of MDG; and to find the best treatment for medical problems, it is not enough to evaluate the results of interventions on morbidity and mortality in clinical studies, but the outcome of interventions on the quality of life is an important criterion in this evaluation [13]. Thus, the surgical process should meet all these guidelines of quality; it should provide the relief of symptoms and improvement in patient's quality of life. The age at marriage should be delayed, female education with knowledge of reproductive health, women empowerment and so on. For prevention of complete prolapse, pessary should be applied in the early stage of UP problem. The measures like pelvic floor exercise or insertion of ring to the uterus can be performed which definitely bring down the incidence of uterine prolapsed. Thus by comprehensive and coordinated actions by the clients, service providers and a whole health service delivery system will have impacts on improving the quality of health care leading to improvement of quality of women's reproductive life.

\section{REFERENCES}

[1] WOREC (1998) Women's Reproductive Health Problems in Rural Nepal. Women's Health Programme, Kathmandu.

[2] Inhorn, M.C. (2006) Defining women's health: A dozen message from more than 150 ethnographies. Medical Anthropology Quarterly, 20, 345-378. http://dx.doi.org/10.1525/maq.2006.20.3.345

[3] Bajracharya, A. (2007) Uterine prolapse: A hidden tragedy for women. The Global Source for Summaries and Reviews.

[4] Institute of Medicine and UNFPA (2006) Status of Reproductive Morbidities in Nepal. Report Submitted to UNFPA, Kathmandu.

[5] CAED (2011) Uterine prolapse study report center for agro-ecology and development Nepal. www.advocacynet.org

[6] UNFPA and Sancharika Samuha (2007) Booklet on uterine prolapse. Kathmandu Sancharika Samuha.

[7] FHD, WHO and SAIPAL (2011) Perception, Experience and Health Outcome of the women who had undergone Uterine Prolapse. Kathmandu Nepal.

[8] Hayward, R.F. (2000) Breaking the Earthenware Jar, Lessons from South Asia to End Violence against Women and Girls. UNICEF, Regional Office for South Asia.

[9] Annandale, E. and Hunt, K. (2000) Gender Inequalities in Health. Open University Press, Bukingham Philadelphia.

[10] World Health Organization (2011) Early marriages, adolescent and young pregnancies. Executive Board, 130th session, Provision agenda items 6.4.

[11] Creel, C.L., Sass, C.J. and Yinger, V.N. (2011) Clientcentered quality: Clients perspectives and barriers to receiving care. New Perspectives on Quality of Care. Population Reference Bureau.

[12] UNFPA (2010) How universal is access to reproductive health? A review of the evidence. Kathmandu.

[13] Wohltjen, H.M. (2011) Making reproductive health meaningful: An anthropological study of planned parenthood personnel in Lexington, KY. 